\begin{tabular}{|l|l|l|l|l|l|}
\hline MUNIBE Antropologia-Arkeologia & $n^{\circ} 66$ & $147-162$ & DONOSTIA & 2015 & ISSN 1132-2217 • eISSN 2172-4555 \\
\hline
\end{tabular}

\title{
La progresión del 'fenómeno' Campaniforme durante el Bronce Medio en el entorno del Sistema Ibérico: el poblado de Valdescusa (Hervías, La Rioja, España)
}

\author{
The progression of the Bell-Beaker 'phenomenon' during the Middle Bronze Age \\ around the Iberian Mountains: the settlement of Valdescusa (Hervías, La Rioja, Spain)
}

PALABRAS CLAVES: Fosa funeraria, poblado, radiocarbono, termoluminiscencia, ADN antiguo

GAKO-HITZAK: Hilobia, herrixka, erradiokarbonoa, termoluminiszentzia, DNA zaharra.

KEY WORDS: Pit burial, settlement, radiocarbon, thermoluminescence, ancient DNA

\section{Carmen ALONSO FERNÁNDEZ(1) \& Javier JIMÉNEZ ECHEVARRÍA(1)}

\section{RESUMEN}

La excavación arqueológica realizada en el hábitat al aire libre de Valdescusa (Hervías, La Rioja, España) pone de relieve la sincronía estratigráfica y cultural entre elementos tradicionalmente considerados como Campaniformes y del Bronce Pleno, actuando como eslabón espaciotemporal entre las síntesis regionales de la Meseta y la Cuenca Alta-Media del Ebro, donde la acotación cronológica del fenómeno campaniforme resulta muy desigual. Esta controvertida perduración subraya la necesidad de regionalizar y periodizar un fenómeno, pretendidamente lineal, cuyos modelos explicativos no encuentran en los escasos lugares de hábitat documentados un punto de convergencia con el esquema de élites y tumbas suntuarias que lo han construido.

\section{LABURPENA}

Valdescusako (Hervías, Errioxa, Espainia) aire zabaleko habitatean egindako indusketa arkeologikoak agerian uzten du tradizioz Kanpaniforme eta Erdialdeko Brontzekotzat hartu diren elementuen arteko sinkronia estratigrafikoa eta kulturala; Ebroren goiko eta erdiko arroaren eta Goi-ordokiaren artean, fenomeno kanpaniformeen kota kronologikoak oso gorabeheratsuak diren tokian, eskualdeko sintesien arteko espazio eta denbora mailako katebegi gisa har daiteke hori. Eztabaida ugari sortu duen datatze horrek agerian utzi du ustez lineala zen fenomenoa eskualdekatu eta daten arabera zehaztu beharra dagoela. Horien azalpen-ereduek ez dute aurkitu dokumentatutako habitat-toki eskasetan eraiki duten eliteen eskemarekin eta luxuzko hobiekin bat egiten duen punturik.

\begin{abstract}
The archaeological excavation in the settlement of Valdescusa (Hervías, La Rioja, Spain) highlights the stratigraphic and cultural synchrony between elements traditionally considered Bell-Beaker and Middle Bronze Age, acting as spatiotemporal link between regional synthesis of la Meseta and Upper-Middle Ebro Basin, where the chronological dimension of the phenomenon is very uneven.

In both sides of the Iberian Mountains and especially in the corridor Upper Duero-Upper Ebro (provinces of La Rioja, Burgos, Soria and Navarra), concentrate atypical archaeological records outside the timeframe established for the peninsular Bell-Beaker period. However, they are no strangers to other contexts that are legitimized in regions such as Galicia, Madrid and Andalucía, and fully accepted in south-eastern France. In the settlement of Valdescusa, radiometric dates situate its validity to $3400 \pm 35 \mathrm{BP}$, in the Middle Bronze Age. Here are documented 41 domestic and funerary structures belonging to a "pits field"; it is the first open-air site excavated in La Rioja. Among the domestic structures exist pits-dumps, post holes and ditches where usually appears Bell-Beaker materials and other productions of "smooth ceramic horizon" own of regional Middle Bronze Age. Among the funerary structures five individual burials in pit are counted, primary deposits of three infants and secondary deposits in juveniles and adults. They all try to burials away from schemes tombs of ancient Bell-Beaker. The datings on radiocarbon and thermoluminescence from the pit E- 45 warn of the contemporaneity of the buried individual and the Bell-Beaker ceramic materials accompanying inside the fill amortization. Thus, a double occupancy and the intrusive nature of these materials are discarded, being present in almost all archaeological structures.

The pottery decorated with Bell-Beaker motifs represents $10 \%$ of the total record in Valdescusa, a percentage that can hardly explain their high symbolic value because to be associated with an everyday household use; is included within the 'Silos style', variety of Ciempozuelos. Another feature present in these deposits is the decorative tradition concerning the ancient Bell-Beaker characters, which incorporates formal innovations, as also seen in the ritual aspect. Economic activities documented in the settlement are agriculture, livestock and hunting, following regional patterns of the time; from the archaeological record is not possible to determine the prevalence of any.

This controversial pervivence underlines the need to regionalize and periodize a phenomenon, supposedly linear, in whose models not found a point of convergence with the scheme of elites and sumptuary tombs who it have built. Only from a bioarchaeological approach may be void, or not, the ethnic idea of a 'Bell-Beaker people' and its different rhythms in the regional, peninsular and european context. The movement of groups seems incontestable in the current state of question for explain the spread of the phenomenon, considering the encouraging results obtained in Central European groups analysed.
\end{abstract}

(1) CRONOS S.C. Arqueología y Patrimonio: Centro Europeo de Empresas e Innovación, Mod. 3, 09007 - Aeropuerto de Villafría (Burgos), Tel.+034947273 472, E-Mail: tecnicos@cronossc.es 


\section{1.- EL YACIMIENTO ARQUEOLÓGICO}

El yacimiento Valdescusa (Hervías, La Rioja) se emplaza en el borde de una plataforma amesetada de perfil llano y $671 \mathrm{~m}$ de altitud, entre el pie de monte de la Sierra La Demanda-Cameros y la depresión del Ebro, relieve co- rrespondiente a un glacis de génesis moderna modelado por el abanico de Hervías, que hacia el sur marca una abrupta caída confiriendo al emplazamiento un alto dominio visual sobre su entorno pero sin fácil defensa (Figuras 1 y 2). En superficie, la ocupación campaniforme se integra dentro de un extenso taller de industria lítica que arranca

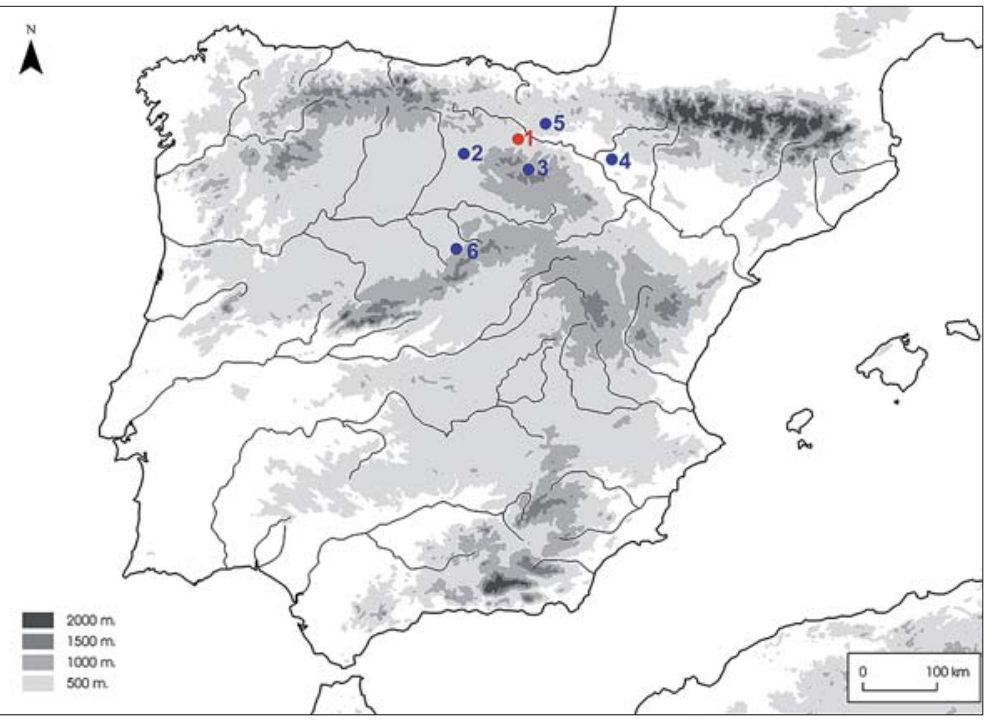

Fig. 1. Situación de los principales yacimientos citados en el texto: 1-Valdescusa (Hervías, La Rioja); 2-Rompizales (Burgos), 3- Cueva Lóbrega, Peña Piel, Tragaluz, Peña Guerra I y II (Sierra de Cameros, La Rioja); 4-Covaza, Picarana, Abejar I, III y IV, Marijuán I y II, Monte Aguilar, Cuatro Cabañas I y Ponchín IV (Bardenas Reales, Navarra); 5-Peña Larga y San Martín (Alava); 6-Arevalillo de Cega (Segovia). / Situation of the principal archaeological sites mentioned in the text: 1-Valdescusa (Hervías, La Rioja); 2-Rompizales (Burgos), 3Cueva Lóbrega, Peña Piel, Tragaluz, Peña Guerra I y II (Sierra de Cameros, La Rioja); 4-Covaza, Picarana, Abejar I, III y IV, Marijuán I y II, Monte Aguilar, Cuatro Cabañas I y Ponchín IV (Bardenas Reales, Navarra); 5-Peña Larga y San Martín (Álava); 6-Arevalillo de Cega (Segovia).

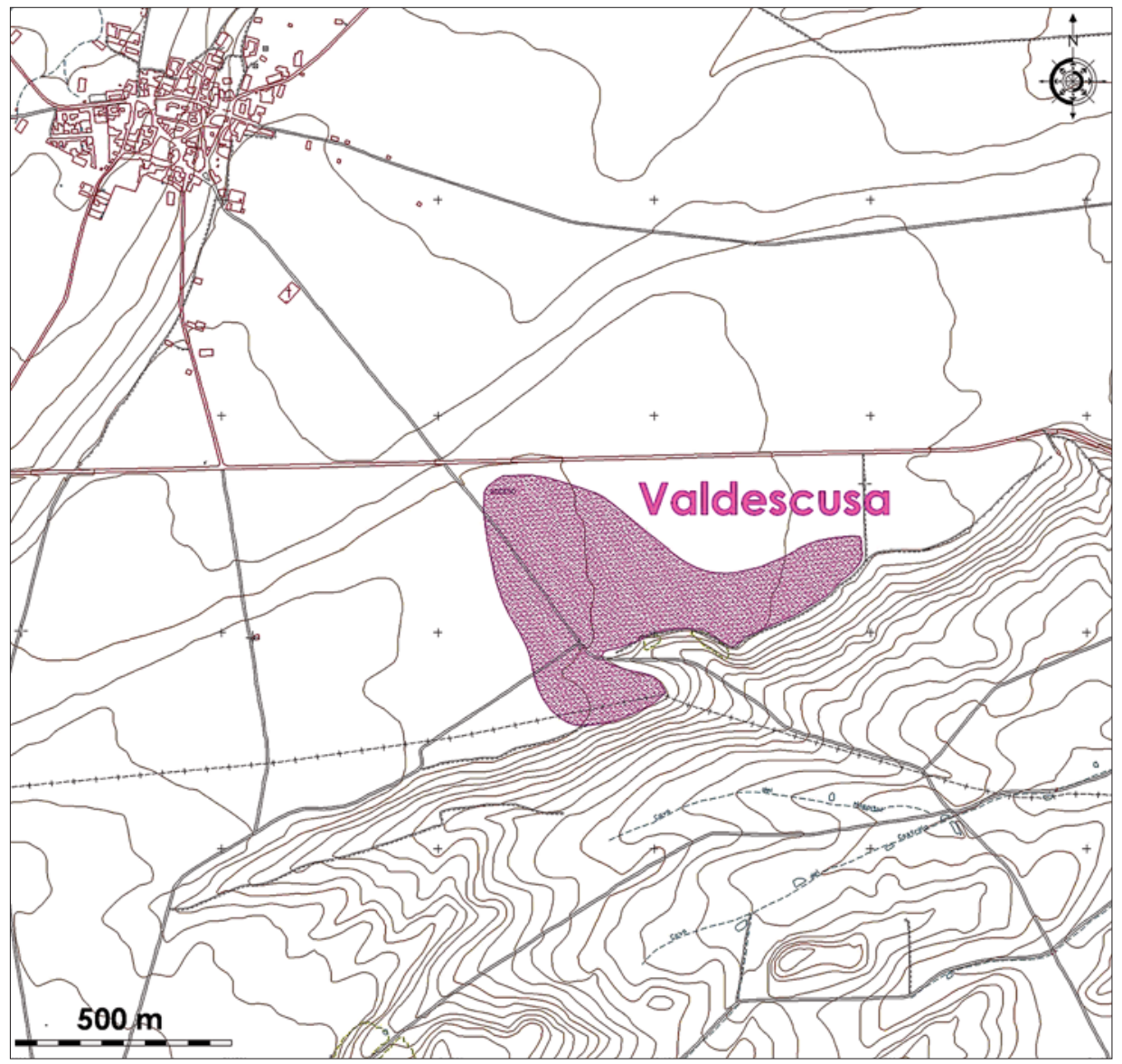

Fig. 2. Localización topográfica y delimitación del yacimiento Valdescusa (Hervías, La Rioja). / Topographic location and delimiting of the site Valdescusa (Hervías, La Rioja). 
desde el Paleolítico Medio y se rastrea hasta etapas tardomedievales (ALONSO, 2013b), reconociéndose con extrema dificultad a pesar del laboreo agrícola de los terrenos; su extensión ha sido estimada en 2,25 ha. El sustrato litológico dominante se compone de margas claras cimentadas con gravas, alternas con inserciones puntuales de arcillas rojas con arenas que claramente han sido evitadas.

La intervención arqueológica se ha centrado en el sector septentrional del poblado, el más retranqueado hacia el interior de la llanura, actuando sobre una superficie de 0,66 ha donde han sido identificadas 41 estructuras negativas que dibujan una 'O' con un amplio espacio interior exento de evidencias, quizás debido a motivos de orden litológico y/o de conservación (Figura 3). Estas estructuras forman parte de un extenso 'campo de hoyos', cuyo análisis individualizado permite su encuadre funcional en silos-basu- reros, hoyos de poste, zanjas y fosas funerarias, que en su conjunto conforman los restos conservados del lugar de habitación campaniforme al aire libre.

\subsection{Estructuras no funerarias}

Trece de estas estructuras responden funcionalmente a silos de almacenamiento, aunque en sus paredes no se han identificado revestimientos o adecuaciones orientadas al aislamiento del interior, ya que el sustrato donde fueron excavados no lo requiere. Se observa un claro predominio de hoyos de planta circular, con diámetros que oscilan entre 88 y 122 cm, aunque también se documentan algunos de tendencia ovalada y polilobulada. Las secciones son mayoritariamente cuenquiformes, con presencia de varias troncocónicas y cilíndricas, y poten-

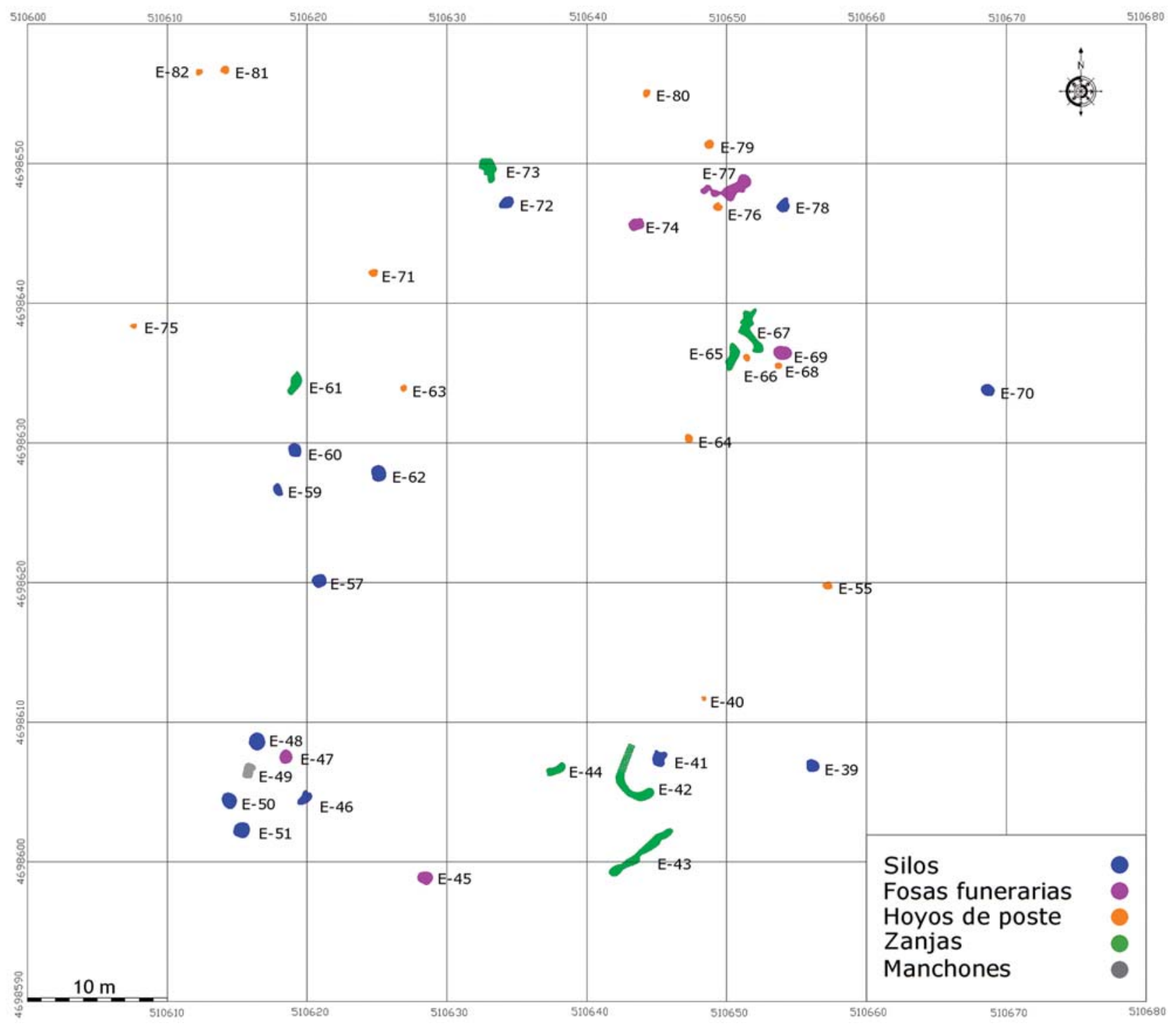

Fig. 3. Planta de la excavación arqueológica del yacimiento Valdescusa (Hervías, La Rioja). / Plant of the archaeological excavation of the site Valdescusa (Hervías, La Rioja). 
cias que normalmente superan los $30 \mathrm{~cm}$, alcanzando en dos estructuras $85 \mathrm{~cm}$. En prácticamente todos los casos aparecen amortizadas como basureros en secuencias rápidas de colmatación antrópica, de uno o dos eventos, aunque también en dos estructuras la sedimentación natural contribuyó a finalizar su colmatación bien de forma parcial (E-57) o total (E-72). Los rellenos de origen antrópico, a menudo cenicientos, atrapan materiales domésticos de desecho, siendo el grupo cerámico el mejor representado frente a la industria lítica y la fauna, las cuales aparecen infrarepresentadas; de cualquier modo, el material no resulta especialmente abundante. Desde el punto de vista de la organización espacial, los silos-basureros dibujan una amplia dispersión dentro del área intervenida, aunque tienden a concentrarse en el sector occidental.

Por su parte, los quince hoyos de poste documentados se distribuyen de forma excéntrica en relación al plano del yacimiento, no apareciendo en asociación con otras subestructuras afines o restos de hogares que indiquen su pertenencia a cabañas, ausentes en el área excavada, pero siempre junto a zanjas y fosas funerarias. La falta de unidades de habitación puede deberse a su localización en otro lugar, quizá más próximo al borde meridional de la plataforma donde se inscribe la zona nuclear del yacimiento, ya que cuenta con mejor dominio visual del entorno. Por otro lado, el laboreo agrícola ha podido eliminar su rastro arqueológico al tratarse frecuentemente de estructuras someras, por lo que algunos de los hoyos de poste identificados pueden ser las únicas evidencias conservadas. Cuentan por lo general con un patrón formal muy similar, con plantas circulares o de ligera tendencia oval y secciones cuenquiformes, siendo su potencia media de $19 \mathrm{~cm}$. El diámetro máximo se sitúa entre los 36 y 64 $\mathrm{cm}$, si bien se observa una brusca tendencia a su reducción en profundidad, con una media de $33 \mathrm{~cm}$, siendo el fondo acorde con grosor del poste y a menudo excéntrico respecto a la boca para facilitar su colocación en un plano inclinado.

Más problemáticas en su interpretación son las siete zanjas o cubetas identificadas, de morfología variada con rangos de longitud entre 117 y $354 \mathrm{~cm}$ y de potencia entre 13 y $59 \mathrm{~cm}$, pero que tienen en común su sección en artesa y una tendencia a la agrupación; estructuras que en algunos yacimientos cumplen funciones delimitadoras, pero que en este caso podrían tratarse de fosas orientadas a la recogida del agua -si bien exentas de revestimientos, simples comederos de ganado o fosas relacionadas con cualquier otra función doméstica auxiliar.

\subsection{Estructuras funerarias}

Entre las estructuras destacan cinco fosas de carácter funerario, cada una de las cuales contiene los restos óseos de un individuo (Figura 4). Con respecto a su morfología, todas ellas presentan planta de tendencia circular cuyo diámetro oscila entre los 83 y los 104 cm, y sección troncocónica o cilíndrica, siendo su potencia variable entre 31 y $114 \mathrm{~cm}$. En cuanto a los rellenos sedimentarios de colmatación, en todos los casos se documentan dos unidades estratigráficas, aunque con algunas matizaciones. Precisamente las variaciones morfológicas y sedimentarias parecen atender a cuestiones de tipo ritual en función de la edad de los individuos, ya que con carácter general se observan dos tipos de enterramiento: uno de juveniles y adultos, y otro de individuos infantiles. Aparentemente, salvo posiblemente la fosa E-45, fueron concebidas para uso funerario y no como estructuras siliformes amortizadas tras su vida útil. Desde el punto de vista ritual se observa la ausencia de preparación o recubrimientos especiales del fondo de la estructura, la colocación cuidada de los individuos y una evidente intencionalidad de ocultación y/o protección de los restos.

Los enterramientos de juveniles (E-77) y adultos (E45) fueron realizados desde el punto de vista estructural en fosas profundas, de desarrollo troncocónico y cilíndrico, y con una cuidada ejecución. La fosa E-77 tiene la peculiaridad de formar parte de una estructura más compleja: está situada en el extremo meridional de una zanja polilobulada de $380 \mathrm{~cm}$ de longitud este-oeste y cuya profundidad oscila entre los 5 y los $15 \mathrm{~cm}$, descartando que se trate de una superposición a juzgar por la homogeneidad de sus rellenos y la ausencia de yuxtaposiciones. En realidad parece una estructura funeraria compleja, quizá no comparable a las recientemente documentadas en la región de Madrid (LIESAU et al., 2008: 111-115) pero posiblemente dentro del mismo concepto.

Los fallecidos fueron depositados en el fondo de las fosas, posteriormente rellenadas con un primer nivel sedimentario que sirvió para cubrir estrictamente los cuerpos.

\begin{tabular}{|l|l|l|l|l|l|}
\hline$N^{\circ}$ & Sexo & Edad de muerte & Tipo & Orientación & Posición \\
\hline E-45 & $\sigma^{7}$ & $25-35$ años & Secundario & Oeste-Este & Decúbito supino \\
\hline E-47 & - & 4 años \pm 12 meses & Primario & Sur-Norte & Decúbito lateral derecho \\
\hline E-69 & - & 6 años \pm 24 meses & Primario & Sur-Norte & Decúbito lateral izquierdo \\
\hline E-74 & 우 & 12 años \pm 36 meses & Primario & Norte-Sur & Decúbito lateral derecho \\
\hline E-77 & 우? & 15 años \pm 36 meses & Secundario & Sur-Norte & Decúbito lateral derecho \\
\hline
\end{tabular}

Tabla 1: Características generales de las inhumaciones del yacimiento Valdescusa. / General characteristics of the burials from site Valdescusa. 

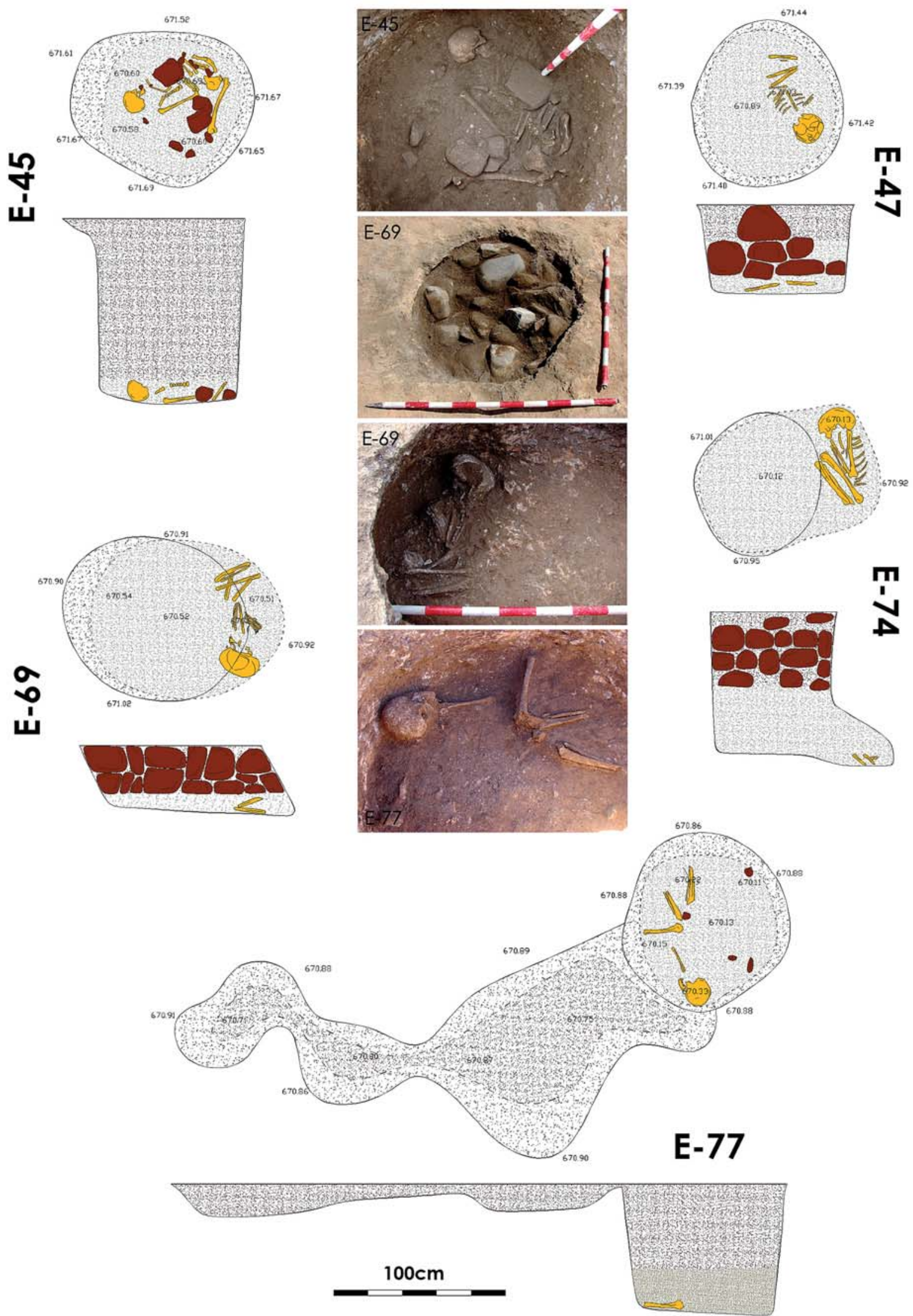

Fig. 4. Estructuras funerarias en fosa del yacimiento Valdescusa. / Burial pits on the site Valdescusa. 
El resto del espacio, la mayor parte, fue colmatado mediante el aporte de un segundo relleno. Aunque en ambos se observa la adición puntual de piedras, principalmente en E-45, no fueron elementos principales en el proceso de sellado de los contenedores funerarios. En los dos casos se tratan de enterramientos secundarios, $y$ todo indica que en el momento de su inhumación definitiva los cuerpos presentaban un alto nivel de descomposición pero conservaban ciertas conexiones anatómicas, compartiendo la presencia de cráneo, mandíbula y parte de las extremidades. Esta práctica, no muy habitual en contextos campaniformes pero que cuenta con amplia distribución geográfica (BERZOSA Y FLORES, 2005: 483; CLOP, 2004: 305; SESMA Y GARCÍA, 2002-2003: 24), debe ser puesta en relación con la práctica de esperar a la descarnación de los cuerpos para recibir sepultura definitiva; una costumbre que tiene su explicación dentro de un funeral entendido como rito de paso, en el que es necesario esperar un tiempo hasta que desaparezca la carne para que el alma abandone definitivamente el mundo de los vivos y viaje al más allá (METCALF Y HUNTINGTON, 1991: 84 y ss).

El individuo de la fosa E-45 es un varón adulto de edad de muerte de entre 25-35 años. Los restos más o menos desmembrados fueron depositados con orientación oesteeste en decúbito supino y de manera cuidada, al menos la cabeza y las extremidades superiores, estas últimas flexionadas sobre el abdomen. Sin embargo, no conserva la pierna derecha, y la izquierda está dividida en dos partes, con el fémur aún en el interior del acetábulo, pero dislocado; también conserva parte de la pelvis, algunas vértebras y costillas, el sacro, las clavículas y parcialmente las escápulas. Fuera de conexión y por encima de los restos mencionados, aparecieron la tibia, algunas falanges y una costilla. Además, entre el sedimento de cubrición superior fue documentada una falange humana infantil, hallazgo que pudiera entenderse bien como resultado de la reutilización del contenedor funerario, bien como una intrusión sedimentaria dentro de la práctica común del traslado de cadáveres constatada a nivel regional desde el Neolítico Antiguo (ALONSO Y JIMÉNEZ, 2014: 48).

El individuo de la fosa E-77, posiblemente una mujer cuya edad de muerte ha sido estimada en 15 años \pm 36 meses, fue depositado junto al perfil occidental de la estructura con orientación sur-norte. En realidad se trata de un conjunto de restos desmembrados, aunque conserva la conexión anatómica entre tibias y peronés. Las porciones fueron colocadas simulando la posición fetal, sobre el costado derecho. En concreto se conserva el cráneo, la mandíbula, el brazo y parte de la escápula derecha, dos costillas y las piernas, pero sin rótulas ni huesos del carpo y tarso.

Por su parte, las tres fosas infantiles documentadas tienen en común que fueron selladas mediante el aporte de piedras cuarcíticas. Para ello fueron seleccionados guijarros de tamaños similares, medio y grande, que fueron dispuestos en dos o más capas formando un encachado en la parte superior de la fosa. Esta protección no descansa directamente sobre los restos humanos, sino que estos fueron cubiertos previamente con un aporte sedi- mentario. El encachado pudo formar parte de un túmulo señalizador, práctica constatada en fosas de la región de Madrid donde parece ser exclusiva de contextos campaniformes (LIESAU et al., 2008: 109). Desde el punto de vista estructural se observan algunas variantes entre las tres fosas: la E-47 es de sección troncocónica muy regular; la E-69 es cilíndrica y con el fondo ligeramente excéntrico, de manera que el perfil oriental se ensancha ligeramente aunque sin llegar a conformar una subcámara o nicho, a pesar de que fue diseñada premeditadamente para alojar al inhumado en este espacio; y la estructura E74 cuenta con un auténtico nicho, excavado en el perfil oriental, con una superficie de $0,25 \mathrm{~m}^{2}$ y una diferencia de amplitud de $21 \mathrm{~cm}$ respecto a la boca.

A diferencia de lo que ocurre en los individuos juveniles y adultos, los enterramientos infantiles son de tipo primario. Los cuerpos fueron depositados en posición fetal, en decúbito lateral derecho o izquierdo, y con orientación norte-sur (E-74) o sur-norte (E-47 y E-69). Como sucede en la fosa E-77, claramente se observa la intención de que los cuerpos ocupen una zona marginal de la estructura. Se tratan de individuos de sexo indeterminado con edades de muerte estimadas en 4 años \pm 12 meses, 6 años \pm 24 meses y 12 años \pm 36 meses, respectivamente.

En el interior de las cinco fosas funerarias han sido recuperados algunos materiales arqueológicos, cuya presencia, al menos con carácter general, no tiene por qué estar necesariamente relacionada con una intencionalidad votiva, ya que pudieron ser introducidos de manera fortuita formado parte del sedimento de relleno. El conjunto está integrado principalmente por pequeños fragmentos cerámicos, en cuatro de las fosas con decoración campaniforme, pero también por un amuleto de hueso, algunos elementos líticos -entre los que cabe mencionar varias láminas, una piedra durmiente de molino de mano y un raspador circular- así como algunos restos óseos faunísticos que en la fosa E-47 pertenecen a un perro.

En la fosa E-45 los restos del inhumado fueron depositados directamente en el fondo, pero sobre varios fragmentos cerámicos y algunas esquirlas óseas, lo que parece indicar una primera intencionalidad de utilizar la estructura como vertedero y que la inhumación se produjo cuando había empezado su colmatación, como sucede en algunas estructuras funerarias similares de la provincia de Madrid (ALIAGA, 2008: 34). En esta inhumación cabe dotar de posible carácter votivo a una primera falange de ovicáprido, decorada en el extremo proximal mediante incisión con un motivo ondulado que recorre el perímetro de la pieza, y la piedra durmiente de molino de mano barquiforme, ambos depositados sobre el finado. Desde el punto de vista ritual también cabe señalar el uso de pigmentos de color anaranjado, aparentemente óxidos de hierro exógenos al contexto geológico del lugar: en esta inhumación, concretamente en la región craneal, y en el individuo de la fosa E-69, en cráneo, húmero izquierdo, fémur y tibia derecha. El uso de pigmentos asociados a contextos funerarios ha sido ampliamente constatado a nivel peninsular durante el Calcolítico y la Edad del Bronce, tanto sobre res- 
tos óseos como objetos (LÓPEZ et al., 2012: 289). Cabe recordar, así mismo, la profusión de pigmentaciones rojizas en botones de perforación en "V" del Campaniforme centroeuropeo (HARRISON, 1980: 51).

En relación a la distribución de las fosas funerarias dentro del yacimiento se observa una cierta posición periférica organizada en dos grupos, uno al norte y otro al sur, constatándose en ambos la presencia de individuos infantiles. A pesar de tratarse de tumbas individuales conservan el vínculo con la colectividad, quedando emplazadas en el mismo espacio que ocupa el poblado, en una posible relación con zanjas y hoyos de poste que, si realmente pertenecieron a cabañas, su asociación sería un testimonio de la incorporación del mundo funerario al doméstico en su sentido más estricto.

\section{2.- LA CULTURA MATERIAL}

\subsection{Cerámica}

La cerámica responde al principal conjunto material presente en el yacimiento, asociado a los rellenos de amortización de 25 de las 41 estructuras que lo integran, con 703 fragmentos que suman un peso total de $6.430 \mathrm{~g}$; estos valores delatan el alto grado de fragmentación de la colección y su poca representatividad numérica.

La cerámica sin decoración campaniforme representa el $77,43 \%$ del número de piezas, con un elenco formal caracterizado por perfiles simples, carenados y, en menor medida, sinuosos, encontrándose decorado apenas un $18 \%$ de las piezas (Figura 5). Entre los carenados se rastrean recipientes típicos del repertorio tradicional campaniforme en forma de vasos y cazuelas, aunque también enmarcados dentro de la tradición del Bronce Medio propia del Valle del Ebro. De hecho encuentra sus mejores paralelos en cerámicas asociadas a lugares campaniformes de habitación al aire libre de la comarca navarra de Bardenas Reales, en concreto Abejar I, III y IV, Marijuán I y II, Monte Aguilar, Cuatro Cabañas I y Ponchín IV (SESMA, 1993); a lugares de habitación en cueva, como el nivel superior de la Sala I y la Sala II de Cueva Lóbrega (BARRIOS, 2004); o a los dólmenes de Peña Guerra I y Peña Guerra II (PÉREZ et al., 1987: 113-124). Al mismo tiempo, destacan las similitudes en cuanto a perfiles y decoración con las cerámicas procedentes de yacimientos del Alto y Medio Valle del Ebro pertenecientes al denominado 'horizonte de cerámicas no decoradas' o 'Bronce clásico', no relacionado con el horizonte Cogotas I y con una cronología sin calibrar que comprende básicamente el rango 3250-3450 BP (SESMA Y GARCÍA, 2002-2003: 29); concretamente con ejemplos como los procedentes del Nivel Il del la cueva riojana de San Bartolomé (RODANÉS, 1999: 67 y ss.), o los poblados navarros al aire libre de Covaza y Picarana (SESMA Y GARCÍA, 2002-2003).

La cerámica con decoración campaniforme se rastrea en el $22,57 \%$ de las piezas con rasgos analizables, que en términos netos corresponde al 10,24\% del número total de fragmentos recuperados en el yacimiento, apareciendo en 11 de las 25 estructuras que contenían registro cerámico junto con las producciones lisas y otras decoradas (Figura 6). Se trata de una representación sobrevenida por el escaso registro material del resto de estructuras donde no se encuentra presente, a menudo con menos de cinco fragmentos. Formalmente se atribuyen a cuencos, vasos, cazuelas y otros recipientes de almacenamiento en proporciones similares, atribución en cualquier caso condicionada por el alto grado de fragmentación de la colección. Tanto por los motivos ornamentales como por las características de su ejecución pueden ser adscritos al denominado 'estilo Silos', variedad de Ciempozuelos no muy extendida en el territorio riojano aunque sí con manifestaciones en Peña Miel Superior, Peña Guerra I (PÉREZ et al., 1987) y Cueva Lóbrega (BARRIOS, 2004), y con importante representación en el área de Tudela-Bardenas Reales asociada a contextos de tipo doméstico (SESMA, 1993). En el ámbito meseteño se circunscribe al reborde montañoso oriental de las provincias de Burgos y Soria, contabilizándose en nuestro caso cuatro piezas con decoración interna en el borde, característica propia de este territorio (GARRIDO, 2000: 121).

Según la tipología definida por R. Garrido Pena en la Meseta, el motivo decorativo más recurrente en Valdescusa es el entramado o reticulado, tanto recto $\left(\mathrm{n}^{\circ} \mathrm{6a}\right)$ como oblicuo ( $n^{\circ} 6 b$ ), seguido por los motivos $12 a$ y $12 b$ que conforman cordones seudoexcisos mediante trazos incisos u hoyitos impresos, respectivamente. También están presentes los motivos $n^{\circ} 2,2$ bis, 5 y 5 bis -a base de frisos estrechos con entramado vertical u oblicuo-, $\mathrm{n}^{\circ} 22$ franja con entramado oblicuo- y n 19 -línea cosida-. Entre los motivos poco frecuentes, que además se encuentran entre los más minoritarios del campaniforme meseteño, destacan los números $8 \mathrm{a}$-serie de ángulos lisos- y 8b serie de ángulos reticulados- (Figura 6.15), este último presente en una pieza que también decora una cazuela funeraria del yacimiento burgalés El Hundido correspondiente a un enterramiento campaniforme intrusivo de cronología antigua (ALONSO, 2013a).

Completando el registro cerámico se cuentan varias piezas (18\%) con decoración no campaniforme a base de barbotina, digitaciones u orejeras, y un pequeño grupo con decoración incisa esquemática a base de una línea simple horizontal, segmentos y líneas paralelas horizontales o diagonales, de aparente reminiscencia calcolítica. También se recuperó el perfil completo de una encella o quesera (Figura 5.13). En todos los casos proceden de rellenos de estructuras que igualmente contienen cerámica campaniforme decorada.

En su conjunto, la cerámica campaniforme comparte importantes características decorativas con producciones procedentes del Alto y Medio Valle del Ebro de las provincias de Álava, La Rioja, Navarra, Burgos y Soria; particularmente con los riojanos Peña Guerra I, Peña Miel Superior y Cueva Lóbrega, los alaveses Peña Larga y San Martín, y muy especialmente con los de carácter doméstico del área Tudela-Bardenas Reales y Soria. Por su parte, el conjunto cerámico sin decoración campaniforme se 


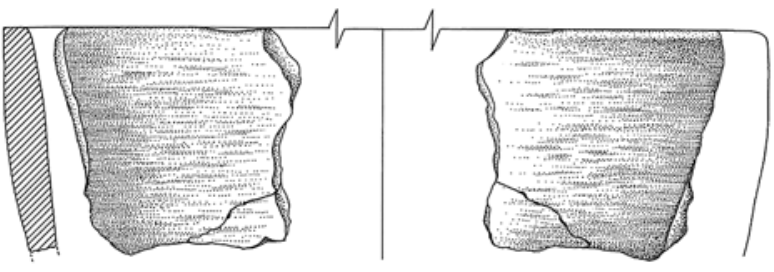

1
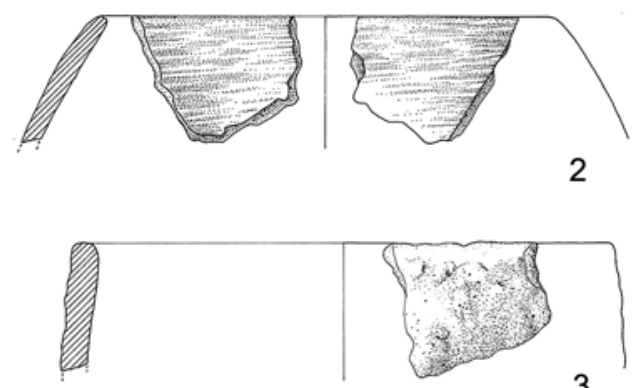

3

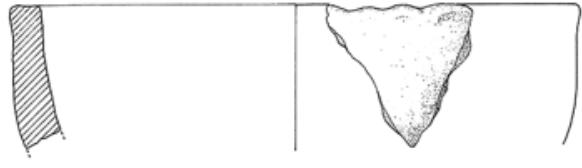

4
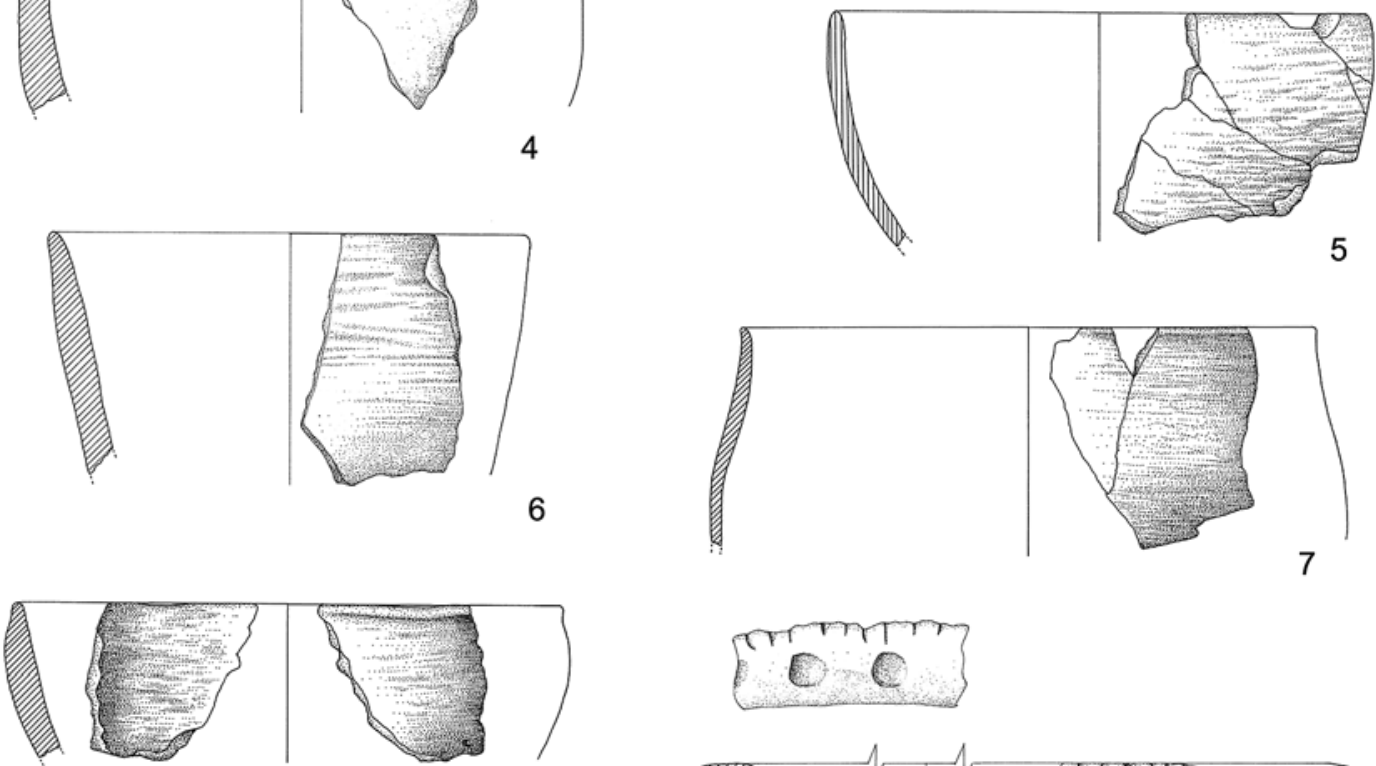

8

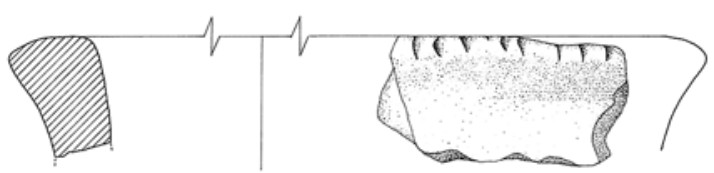

9
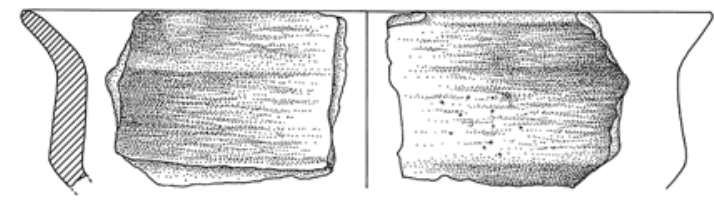

10

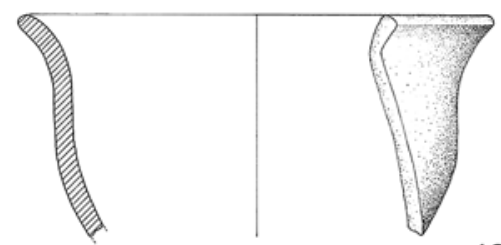

12
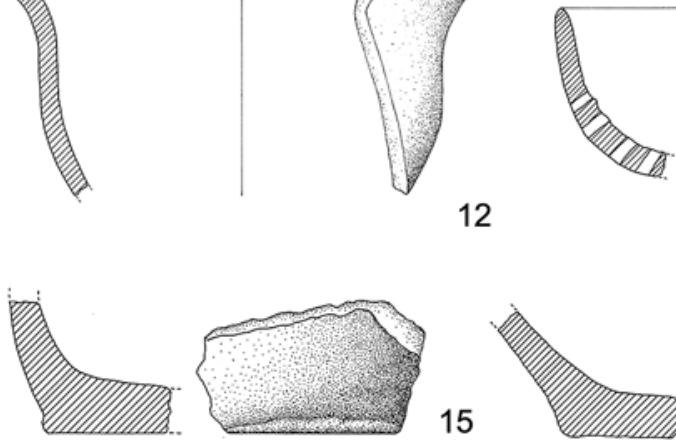

15
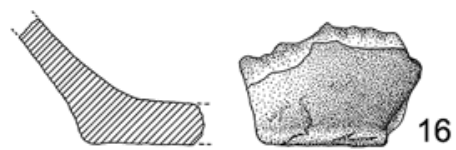

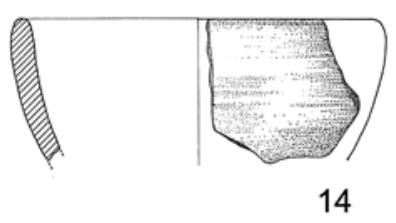

13
11
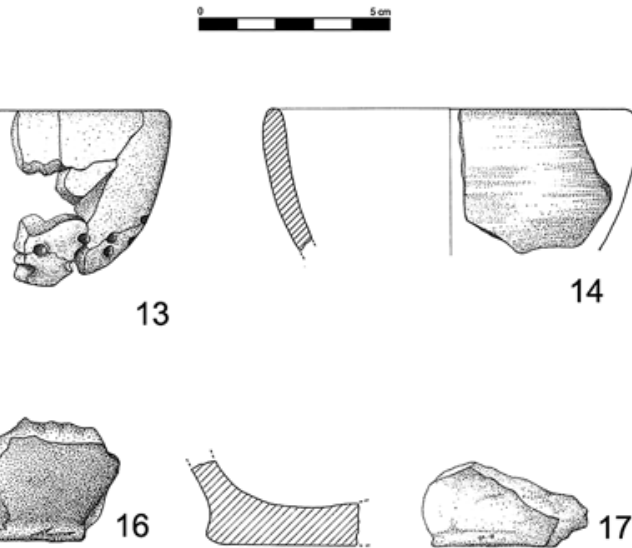

Fig. 5. Cerámicas sin decoración campaniforme procedentes del yacimiento Valdescusa. / Ceramics without Bell-Beaker decoration proceeding from the site Valdescusa. 

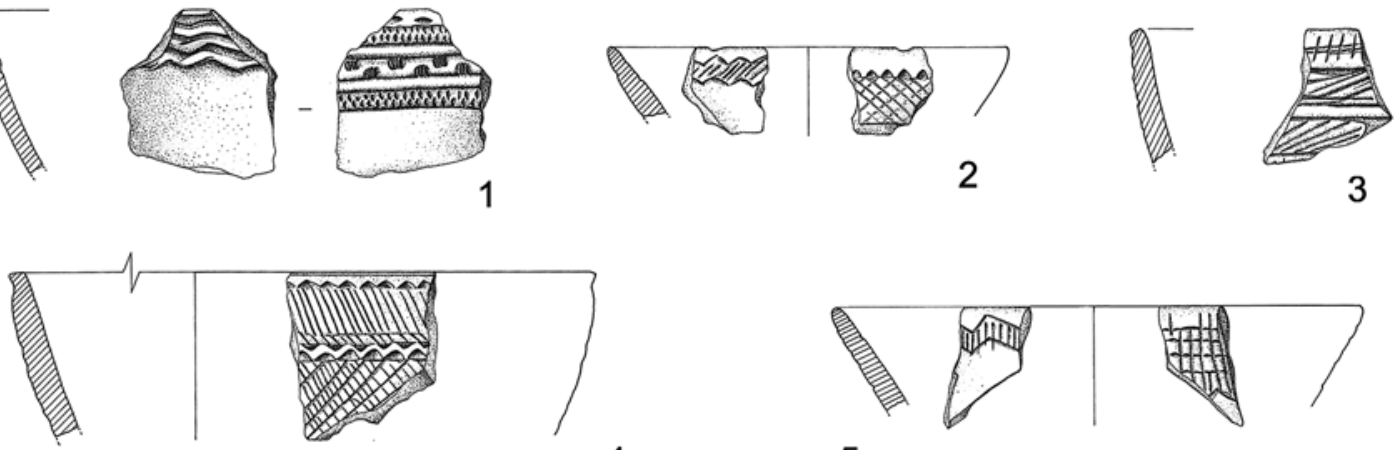

1

2

3
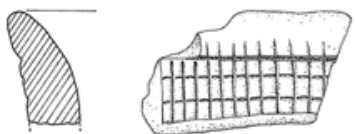

6

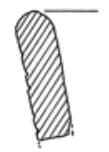

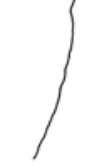

4

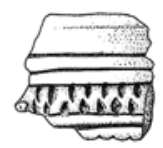

7

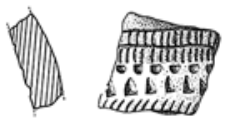

11
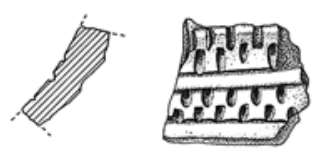

12

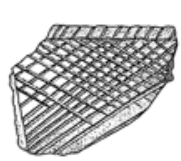

16
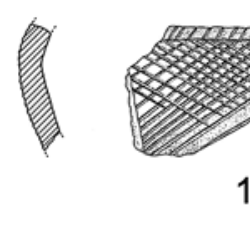

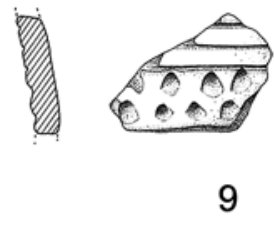

8

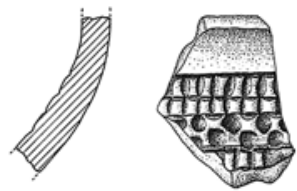

13

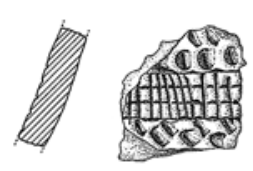

14
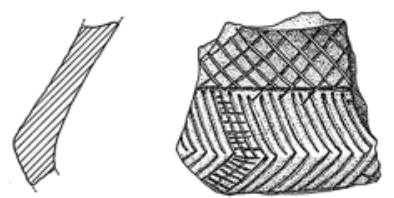

15

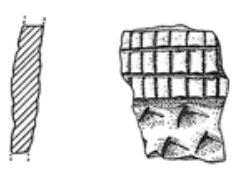

17

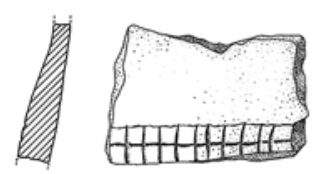

18
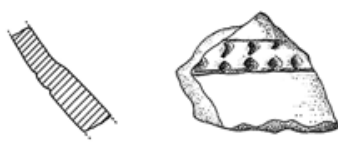

19

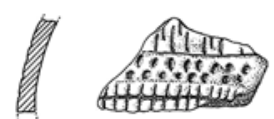

20

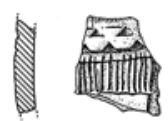

21

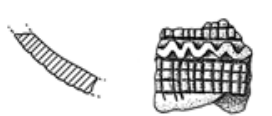

22

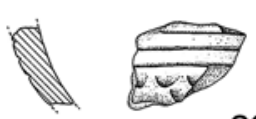

23
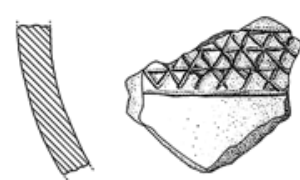

24

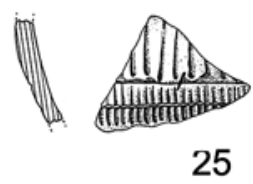

25

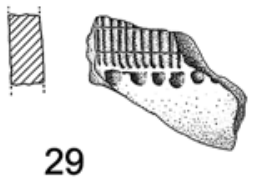

29

26

27

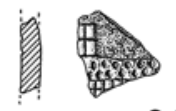

31

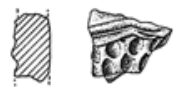

32
28

-

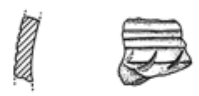

33

Fig. 6. Cerámicas con decoración campaniforme procedentes del yacimiento Valdescusa. / Ceramics with Bell-Beaker decoration proceeding from the site Valdescusa. 
ajusta a las características generales que definen el 'horizonte de cerámicas no decoradas', descrito como un horizonte intermedio entre Ciempozuelos/Bronce Antiguo y Bronce Pleno/Cogotas I (RODANÉS, 1999: 166), cuya presencia en Valdescusa descarta una doble ocupación -una campaniforme previa y otra no campaniforme-, como se desarrolla más adelante.

En suma, el registro cerámico de Valdescusa debe entenderse dentro de una tradición ceramista ajena a los elementos formales y decorativos propios de Protocogotas, que sí se constata en asentamientos afines riojanos relativamente próximos como Majada Londeras de Tobía (CENICEROS, 2000: 7) o Peña Miel Superior. Esta tradición queda patente en la permanencia de la decoración campaniforme en fechas avanzadas y asociada, en cuanto al resto del material cerámico, a producciones que vienen a definir el Bronce Pleno en muchos yacimientos del Valle del Ebro.

\subsection{Industria lítica}

El escaso conjunto lítico recuperado en el interior de las estructuras excavadas está integrado por 17 piezas de sílex, 6 de cuarcita y 1 molino de arenisca. Con respecto a los elementos sobre sílex, mayoritariamente se tratan de lascas simples, nueve en concreto, de las cuales dos son laminares; todas carecen de retoque excepto una pieza de tendencia puntiforme, sección triangular y talón diedro con retoque simple. Los únicos útiles documentados son un raspador circular de 19 mm de diámetro realizado sobre sílex negro y dos láminas de doble dorso. Por otro lado se documentan dos laminillas sin retocar, dos núcleos poliédricos con extracción de lascas y laminillas, y un descortece.

Sobre cuarcita han sido recuperadas seis piezas, integradas por tres lascas sin retocar; un núcleo piramidal con extracción de lascas; un núcleo reutilizado como percutor realizado sobre canto ovalado de cuarcita, con extracción de lascas longitudinales y señales de percusión en los dos polos; y por último, un núcleo de cuarcita poliédrico patinado, de $55 \mathrm{~mm}$ de diámetro, con extracción de lascas, perteneciente a la ocupación musteriense e incorporado al relleno de la fosa E-65 (ALONSO, 2013b: 141).

\subsection{Industria ósea}

En la inhumación de la fosa E-45 ha sido recuperada una primera falange de ovicáprido, posiblemente de naturaleza votiva, perteneciente a un individuo subadulto. La sutura de la fusión epifisaria, prácticamente completa, ha sido retallada de forma premeditada en tres de sus caras dando como resultado un motivo ondulado que recorre el perímetro de la pieza (Figura 7). Este tipo de elementos, que cuentan con una amplia distribución geográfica a lo largo de la Prehistoria Reciente en Europa occidental, son escasos en el norte peninsular si lo comparamos con los numerosos hallazgos procedentes del ámbito meridional en forma de ídolos-falange (MAICAS, 2007: 115).

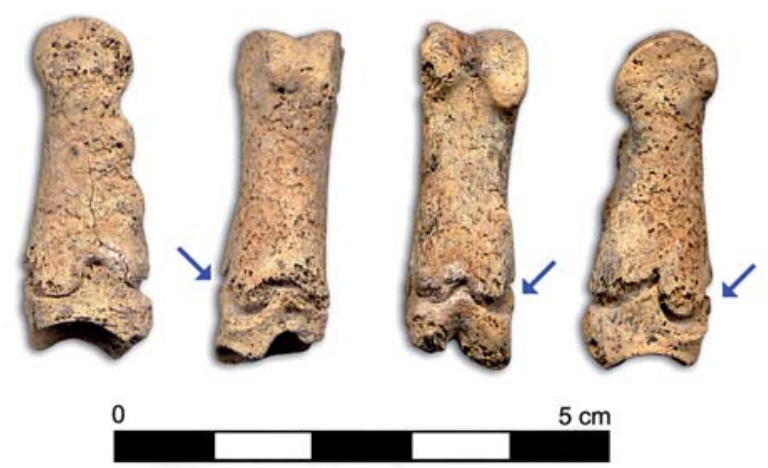

Fig. 7. Primera falange de ovicáprido procedente de la inhumación E-45 de Valdescusa. / The first phalanx of sheep-goat proceeding from the burial E-45 of Valdescusa.

\subsection{Fauna}

El número de estructuras negativas que cuentan entre sus rellenos con restos óseos faunísticos es muy reducido, únicamente seis, siendo muy escasos -72 fragmentos - y con mal estado de preservación. Evidentemente se trata de una muestra insuficiente para hacer valoraciones relacionadas con la dieta o con la preferencia de determinadas especies ganaderas, si bien es cierto que su baja presencia constituye una particularidad que informa sobre el espectro dietético de los moradores del poblado. Su deficiente estado de conservación, al igual que en los restos óseos humanos, quizás obedezca al tipo de sustrato de los rellenos donde se alojan, por lo que en origen su número pudo ser superior.

Atendiendo a las especies identificadas, si exceptuamos las pequeñas esquirlas de difícil adscripción, únicamente cabe mencionar un fragmento de vértebra cervical de équido (E-39), un diente de herbívoro indeterminado (E-45), y los restos de perro (Canis familiaris) y zorro (Vulpes vulpes) procedentes de la fosa funeraria E-47 y del silo E-62, respectivamente. Los primeros, que aparecieron sin conexión anatómica y muy fragmentados, están integrados por varias piezas dentales, un fragmento mandibular, varias costillas y fragmentos de huesos largos (de húmero y ulna). Los restos de zorro se corresponden con la pata izquierda (carpo) de un macho adulto en conexión anatómica. Ambos se tratan de depósitos frecuentes en contextos de la Edad del Bronce, cuyas últimas propuestas plantean un encuadre con prácticas simbólicas donde los cánidos cobrarían protagonismo (LIESAU, ESPARZA Y SÁNCHEZ, 2014).

\subsection{Análisis antropológico: paleopatologías}

El estudio paleopatológico de los cinco individuos únicamente ha deparado resultados reseñables en el hombre adulto (E-45). En este caso, lo más llamativo es la patología dental y la existencia de un traumatismo en la mandíbula, que pudo ser parte de la causa de la muerte. También han sido identificados algunos marcadores de es- 
trés ocupacional, que informan sobre la actividad física realizada a lo largo de su vida.

Con carácter general y tanto a nivel maxilar como mandibular, se observa un proceso de periodontitis ligera. Con respecto a los terceros molares, en el caso de los maxilares están sin ocluir, mientras que en el maxilar derecho, el único conservado, se observa una anomalía con respecto al tamaño, muy pequeño en este caso y rastreable también en el izquierdo a la vista de las dimensiones de la zona alveolar, que podría tener origen genético. Como resultado de un fuerte traumatismo, se observa la fractura completa ante mortem de la mandíbula, con trayectoria diagonal entre el punto sinfisario y la zona alveolar a la altura de Pm1 izquierdo. La rotura supuso la pérdida del canino y de los dos incisivos izquierdos, además de derivar en un proceso infeccioso alveolar localizado en esta zona. El plano de fractura es ondulante y no hay unión del callo primario, lo que significa que la lesión se produjo entre 2 y 3 meses antes de la muerte. También se observa osteólisis en la totalidad de la fractura y neoformación en el mentón. Por último, y siguiendo con la mandíbula, se observan varias caries.

En el esqueleto prostcraneal ha sido identificado un ligero proceso artrítico en la columna vertebral, con formación de pequeños osteofitos en los discos vertebrales cervicales $\mathrm{C}_{2}$ y $\mathrm{C}_{3}$. Por último, en la clavícula derecha se evidencia enthesopatía en la tuberosidad costo-clavicular asociada a fuerte actividad de la cintura escapular. La lateralidad de este marcador de estrés ocupacional determina que el individuo posiblemente era diestro.

\subsection{ADN antiguo}

Los cinco individuos humanos documentados en Valdescusa se han integrado en el proyecto interdisciplinar titulado 'Reconstrucción de la dinámica de la población procesos en la Península Ibérica entre el Neolítico y la Edad del Bronce Antiguo a través de los análisis de ADN antiguo', dirigido por Kurt W. Alt, del Instituto de Antropología de la Universidad de Mainz. Este proyecto tiene como objetivo estudiar y revelar posibles cambios o eventos dinámicos de población detrás los cambios culturales del Neolítico, Calcolítico y la Edad del Bronce peninsulares. La preservación de los restos esqueléticos del yacimiento para estudios de genética molecular ha sido excepcional dentro de la región norte. En las cinco muestras el ADNmt se secuenció con éxito, revelando haplogrupos $\mathrm{J}$ (individuales 2, 4, y 5), HV (individuales 3) y U5B (individuales 1) que, en su mayor parte, representan haplogrupos de origen neolítico típicos de Europa occidental. Los resultados finales dentro del mosaico peninsular están pendientes de su combinación en el análisis estadístico proyectado para el gran papel genético de las muestras españolas.

\section{3.- VALORACIÓN CRONO-ESTRATIGRÁFICA}

Como habitualmente concurre en los lugares de hábitat al aire libre conformados por "campos de hoyos", no existe tampoco en Valdescusa un hilo conductor que permita correlacionar en el tiempo las distintas estructuras negativas que configuran el yacimiento. La total ausencia de yuxtaposición de fosas y de depósitos necesarios para establecer una mínima sucesión horizontal, conduce a que la estratigrafía se reduzca a una sucesión de eventos individuales en la formación de cada estructura. Tan solo la caracterización de los materiales arqueológicos, y en especial del grupo cerámico, permiten establecer una asociación entre las distintas unidades arqueológicas, que aquí presenta el problema añadido de la comparecencia de materiales claramente adscribibles al mundo Campaniforme y otros al Bronce Pleno. Según los apriorismos de una amplia mayoría historiográfica, los primeros serían de cronología más antigua y, por lo tanto, potencialmente intrusivos en los rellenos que amortizan las estructuras posteriores.

Para obtener una valoración empírica que centrase la cuestión cronológica, se obtuvo una datación radiocarbónica del individuo de la fosa E-45 (Ua-36345), la cual aportó una fecha $3400 \pm 35$ BP y un rango cronológico calibrado a 2 o 1780-1610 cal BC (OxCal v.3.10, Bronck Ramsey, 2005). Este lapso temporal enmarca en un momento pleno del Bronce Medio a este sector del yacimiento, si bien ajeno a la tradición ceramista Protocogotas propia de la Meseta, cuyo desarrollo tendría lugar hacia 1750-1500 cal BC (ABARQUERO, 2005: 65; ALONSO Y JIMÉNEZ, 2012a: 374). Así podría quedar cómodamente resuelta la interpretación del yacimiento, ya que el principal contingente material y los caracteres de los enterramientos se alejan de la secular compostura de las tumbas campaniformes, con suntuosos materiales y ajenas a la manipulación de los cuerpos. No obstante, en Valdescusa se repite una circunstancia ya constatada en otros hábitat del entorno riojano en cueva: materiales campaniformes siempre conviviendo con otros etiquetados como morfotipos propios de la Edad del Bronce y no pocas veces interpretados como intrusiones dentro de la dinámica de pluriestratificación tan frecuente en los lugares domésticos en cavidad. Por otro lado, asalta la duda sobre la existencia de dos ocupaciones diferenciadas en el tiempo toda vez no existen estructuras que contengan sólo registro campaniforme, a la vez que en superficie el yacimiento resulta invisible y no se rastrean materiales de una u otra filiación indicadores siquiera de una tibia ocupación previa sin estructuras.

La resolución de esta cuestión, sin otros criterios estratigráficos posibles, pasa por la verificación cronológica de las muestras cerámicas mediante el análisis de termoluminiscencia (TL), que ha sido llevada a cabo sobre tres piezas significativas procedentes de tres contextos estratigráficos distintos. La primera se realizó a partir de un fragmento campaniforme procedente del nivel del relleno basal de la inhumación E-45 (MADN-6391BIN), en contacto con el difunto, lo que permitiría establecer la desviación con la prueba de radiocarbono obtenida y determinar la sincronía o diacronía de la inhumación con los rellenos que la amortizan (Figura 6.5). Una segunda muestra se obtuvo de un fragmento cerámico de la unidad estratigráfica 
superior (MADN-6394BIN), atribuible indistintamente a cualquiera de los dos conjuntos cerámicos diferenciados del yacimiento (Figura 5.1); en este caso, corroboraría, o no, la datación obtenida en la muestra precedente. La tercera muestra se realizó sobre un perfil cerámico característico del 'horizonte de cerámicas no decoradas' atribuible al Bronce Medio (MADN-6392BIN), cuya reconstrucción morfológica descarta su filiación con un vaso campaniforme liso (Figura 5.11). Dada la fragmentación de la colección, esta pieza procede del relleno de otra estructura funeraria (E-74) que también contiene materiales campaniformes, permitiendo de esta forma avanzar en su aproximación cronológica y en la estratigrafía horizontal del yacimiento. En la siguiente tabla se muestran los resultados obtenidos:

\begin{tabular}{|l|c|c|c|c|}
\hline Ref. Lab. & Ref. Ycto & Fecha BP & Fecha cal BC & Rangos cal BC \\
\hline MADN-6394BIN & VDE.E45.1.18 & $3629 \pm 251$ & $1679 \pm 251$ & $1930-1428$ \\
\hline MADN-6391BIN & VDE.E45.2.01 & $3629 \pm 191$ & $1679 \pm 191$ & $1870-1488$ \\
\hline MADN-6392BIN & VDE.E74.1.01 & $3479 \pm 209$ & $1529 \pm 209$ & $1738-1320$ \\
\hline
\end{tabular}

Tabla 2: Dataciones por termoluminiscencia del yacimiento Valdescusa. / Thermoluminiscence dating from the archeological site Valdescusa.

La primera observación que nos proporciona el muestreo de TL es la coherencia temporal de las dos piezas procedentes de la estructura funeraria E-45, cuya fecha mediana es coincidente a pesar de su distinta composición mineralógica. A la hora de abordar la comparación con la fecha radiocarbónica se han tenido que unificar los valores sobre el rango calibrado, dado que las fechas sin calibrar (BP, $\mathrm{AC}$ ) no resultan un criterio homogéneo frente a la $\mathrm{TL}$, que ofrece valores absolutos. Por otro lado, las dos primeras fechas obtenidas por TL, procedentes de E-45, deben ser objeto de un ajuste en el rango temporal más moderno aplicando un criterio estratigráfico-bayesiano, por el cual los materiales que amortizan al enterramiento no pueden ser más modernos que este. Tras esta corrección, apreciamos una extraordinaria coherencia entre la datación del inhumado y el material cerámico campaniforme que le acompaña, con una reducida diferencia en la desviación estadística a techo, que incluso podrían ajustarse en función del momento al que se refieren cada una de ellas cocción del vaso (TL) y muerte del inhumado (C14)-:

\begin{tabular}{|l|c|c|c|c|}
\hline Método & Ref. Lab. & $\begin{array}{c}\text { Fecha } \\
\text { cal BC }\end{array}$ & $\begin{array}{c}\text { Rangos } \\
\text { ajustados }\end{array}$ & $\begin{array}{c}\text { Ajuste fecha } \\
\text { cal BC }\end{array}$ \\
\hline TL & MADN-6391BIN & $1679 \pm 191$ & $1870-1610$ & $1740 \pm 130$ \\
\hline C14 & Ua-36345 & $1695 \pm 85$ & $1780-1610$ & $1695 \pm 85$ \\
\hline
\end{tabular}

Tabla 3: Ajuste bayesiano de la cronológica absoluta de la UE funeraria (fosa E-45). / Bayesian adjustment of the absolute chronology of the funeral UE (pit E-45).

Considerando la coherencia temporal de ambas dataciones y la ausencia de indicios estratigráficos que avalen una ocupación campaniforme anterior, la inhumación y el registro material que la acompaña deben ser entendidos dentro de una misma secuencia temporal. Al mismo tiempo, los resultados obtenidos en la estructura E-74, ligeramente más moderna y donde igualmente compadecen materiales de una y otra filiación cultural, vienen a aseverar la progresión temporal de la ocupación del yacimiento.

En suma, Valdescusa puede ser adscrito a un lugar de habitación vigente en el segundo cuarto del II milenio cal $\mathrm{BC}$, enmarcado culturalmente en el Bronce Medio, ocupando un nicho de paramera donde las estrategias de subsistencia que se arbitran permiten acercarnos a reconstruir una economía diversificada, no muy diferente a priori en el modelo de asentamientos concurrentes a nivel regional. La organización del hábitat, sin yuxtaposiciones de estructuras ni estratigrafía vertical, podría apuntar cierto ordenamiento en la disposición a partir de grupos de estructuras que orbitan hacia un espacio común exento, quizás en orden a distintas unidades domésticas si tenemos en cuenta la relación de fosas de inhumación y silos. A la vista de todos los indicadores cronológicos y de cultura material, su vigencia temporal no rebasaría el Bronce Pleno.

\section{4.- EL CAMPANIFORME Y LA CUESTIÓN CRO- NOLÓGICA: UN VIEJO DEBATE A REVISAR}

La acotación cronológica de la otrora cultura Campaniforme, hoy reducida a fenómeno, ha centrado un viejo debate por la diversidad de las expresiones y la discriminación de las dataciones que han ofrecido un escaso universo de yacimientos en la región central de la Península Ibérica. Un punto de partida equilibrado se puede tomar del estado de la cuestión en base a las distintas compilaciones regionales recogidas en el congreso de 'El Campaniforme en la Península Ibérica y su contexto europeo' de 2005, desarrolladas por R. Pena, M. Rojo e I. García para la Meseta Central, y por A. Alday para la Alta y Media Cuenca del Ebro (AMCE), cuyas propuestas no han avanzado sustancialmente tras los diez años transcurridos. Valdescusa se inserta en los lindes de ambas regiones biogeográficas, por lo que su análisis merece especial consideración.

Para el territorio meseteño y a partir de los límites que impone la cronología $\mathrm{C} 14$, parece que no existen fisuras en enmarcar lo campaniforme entre 2500-2000 cal BC, concentrándose el conjunto de doce fechas radiocarbónicas que integran el espectro de análisis entre el rango 2200-2000 cal BC, fundamentalmente asociadas en la cuenca del Duero a cerámicas del estilo Ciempozuelos (GARRIDO, ROJO Y GARCíA, 2005: 425-426). Culturalmente, este rango cronológico mayor se inscribe entre el final del Calcolítico y durante buena parte del Bronce Antiguo, momento este último que a escala regional podría enmarcarse entre 2400/2300 - 1800 cal $\mathrm{BC}$ si tomamos como fecha válida de inicio de Protocogotas hacia 1750 cal BC (ABARQUERO, 2005: 65). Algunas fechas disonantes consideradas polémicas podrían romper esta homogeneidad para el elenco campaniforme meseteño: Cueva de Arevalillo de Cega $(3520 \pm 140$ BP, $3400 \pm 50$ BP y 
$3290 \pm 50$ BP) atribuidas a grupos postcampaniformes por su cronología tardía enmarcada en el Bronce Medio; y Cueva de la Mora en Somaén $(4620 \pm 130$ BP y $4730 \pm 130$ BP) con fechas muy discutidas que retrasarían el inicio del fenómeno al Neolítico Final. Estos extremos cronológicos fueron defendidos precisamente por M.D. Fernández-Possé para acotar cronológicamente el Campaniforme en la Meseta (FERNÁNDEZ-POSSÉ, 1981), aunque sin aceptación entre quienes vienen moderando hoy el debate.

En lo que respecta a la cronología en la AMCE, la certidumbre meseteña se transforma en un cúmulo de cuestiones sin resolver que dotan al Campaniforme de un espectro de rango amplio, próximo a 1500 años, enmarcado de forma orientativa entre 3300 y 1800 cal BC (45503350 BP) a partir de 24 muestras radiocarbónicas (ALDAY, 2005: 274). Este rango lo sitúa culturalmente entre los inicios del Calcolítico y las postrimerías del Bronce Antiguo, donde las fechas que se postulan para el inicio del Bronce Medio resultan similares a las de contextos meseteños (RODANÉS, 1999: 168). Dentro de esta extensa región, existen registros estratigráficos tradicionalmente considerados como dudosos por ofrecer materiales campaniformes insertos en niveles avanzados de la Edad del Bronce. Tal sería el caso de los yacimientos riojanos de Cueva Lóbrega y Peña Miel Superior (PÉREZ et al., 1987: 136), sobre los que no faltan voces que apuntan una situación retardaria del campaniforme en el Sistema Ibérico que penetraría en el Bronce Pleno (BARRIOS, 2004: 109), o el resultado de una aparente sucesión bajo el sesgo que imprimen las escasas secuencias estratigráficas con las que se cuenta (RODANÉS, 1999: 166-168). Es tal la personalidad cerámica de la comarca riojana de Cameros, con morfotipos seriados bajo los cánones de Ciempozuelos, que se ha llegado a plantear la posible existencia de un taller (ALDAY, 2005: 276).

Según el espectro cronológico de las muestras radiocarbónicas campaniformes en la AMCE, Valdescusa se sitúa en el techo más moderno (Figura 8). Dentro de este marco cronológico interesa destacar dos fechas por pertenecer a yacimientos espacialmente cercanos, encontrarse entre los estilísticamente más próximos y contar con dataciones igualmente afines, ambos de carácter megalítico: Peña Guerra I, donde dos pruebas de radiocarbono realizadas sobre huesos humanos del corredor en el Nivel b (CSIC-627A y CSIC-627B) han proporcionado el rango 1940-1600 cal BC; y Peña Guerra II, en este caso a partir de muestras tomadas en el Nivel II de la cámara central (CSIC-617b), fechado con un rango 1880-1520 cal BC (NARVARTE, 2005: 210, 217). A estas fechas cabría añadir la procedente del Nivel II de la riojana cueva de San Bartolomé, asociada al 'horizonte de cerámicas no decoradas', que de alguna manera ha servido para explicar el lapso entre Ciempozuelos y Cogotas I, con una fecha calibrada 1880-1688 cal BC (RODANÉS, 1999: 66), en clara conexión con la producción de la cerámica sin decoración campaniforme de nuestro yacimiento.

Valdescusa se inserta cronológica y culturalmente ahí, uno de los escasos poblados al aire libre documentado en

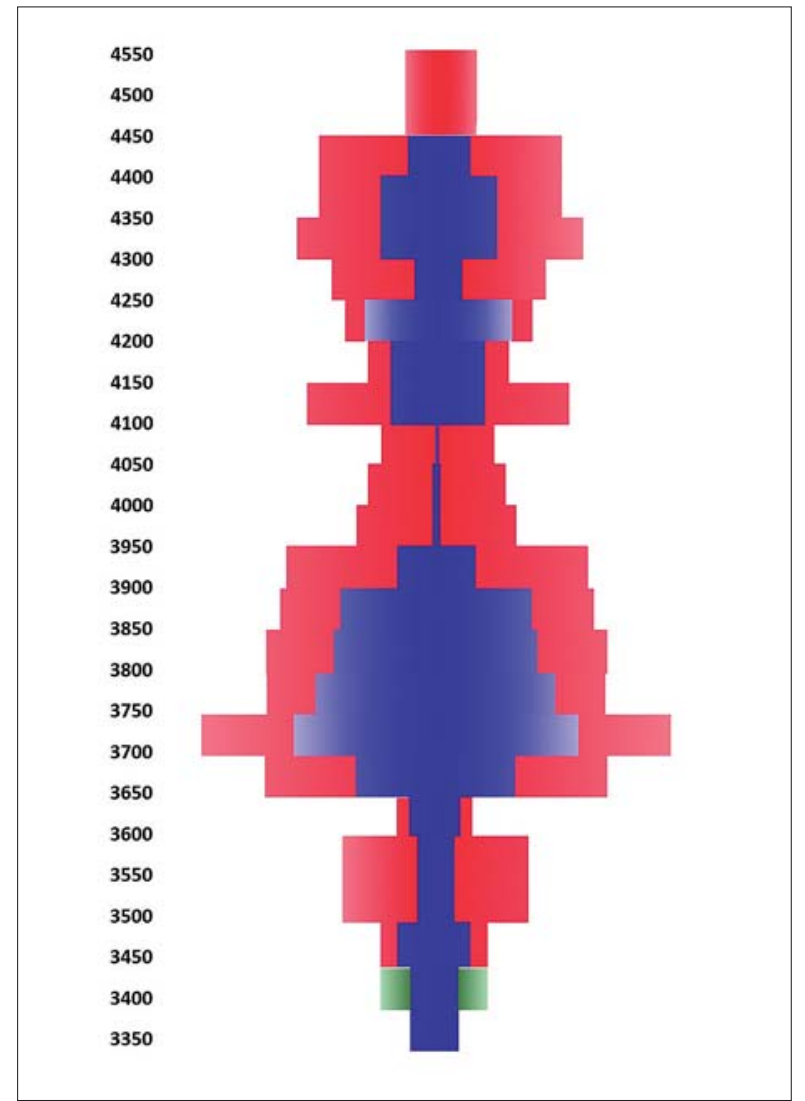

Fig. 8. Situación del yacimiento Valdescusa en el espectro radiocronológico ponderado (BP) de contextos campaniformes en la Alta y Media Cuenca del Ebro, según compilación de A. Alday (2005: 281). En verde, Valdescusa; en azul, lugares funerarios abiertos; y en rojo, depósitos de habitación y funerarios cerrados. / Situation of the site Valdescusa in the chronological weighted spectrum (BP) of Bell-Beaker contexts in the High and Middle Ebro's Valley, according to compilation of A. Alday (2005: 281). In green, Valdescusa; in blue, funeral opened places; and in red, domestic contexts and closed funeral sites.

una extensa zona entre el sur alavés-comarca mirandesa (CAMPILLO, 2000-2002; ALDAY, 1996) y la concentración navarra de Tudela-Bardenas Reales (SESMA, 1993), sirviendo de eslabón a los registros estratigráficos de una región con personalidad propia. Este espacio se abre al mismo tiempo a la región biogeográfica de la Meseta, inmediato a una línea cultural imaginaria de frontera trazada por el interfluvio Oja/Najerilla, poco permeable a la cultura Cogotas I y límite entre su zona nuclear y de contacto hasta el Bronce Final (ALONSO Y JIMÉNEZ, 2012b: 405).

\section{5.- HACIA UNA DIMENSIÓN REAL DE LO CAM- PANIFORME}

El poblado de Valdescusa es un ejemplo más a añadir al creciente corpus de yacimientos donde lo campaniforme progresa sin fisuras en el marco cultural del Bronce Medio, nexo entre el Valle del Ebro y el propio conjunto meseteño. De forma sumaria se ha querido ver esta prolongación temporal como un hecho anómalo en contraposición a lo que se asumía de forma natural en re- 
giones vecinas, como el epicampaniforme meridional francés (BENZ, STRAHM Y VAN WILLIGEN, 1998). Valdescusa es portador de una realidad que ya ha sido objetivada en el registro arqueológico peninsular al menos en Galicia, Andalucía y la región de Madrid, con una penetración que se produce incluso en el Bronce Final (SÁNCHEZ Y GALÁN, 2010) y cuya herencia no pocas veces se ha querido ver en los motivos decorativos Cogotas I. El nuevo concepto que introduce el grupo cultural cogoteño, con la incorporación de vajilla de lujo para usos primarios (ABARQUERO, 2005: 512), sin duda tiene su mejor antecedente en los poblados campaniformes, en general poco estudiados y a menudo disociados de los conjuntos funerarios, receptores del principal protagonismo en el análisis del fenómeno para explicar las estructuras sociales basadas en élites y elementos de prestigio, con modelos difícilmente traspolables a los lugares de hábitat. De ahí su intencional olvido en las síntesis regionales.

Así, Valdescusa presenta no menos del 10\% del cómputo total de vajilla con decoraciones propias que definen 'lo campaniforme', valor que se aleja de los modelos explicativos ad hoc cuando no existe relación con tumbas suntuosas o contextos rituales, como es el caso. Se trata de un valor muy similar a otro de los escasos poblados excavados del contexto espacial que ahora se analiza, el yacimiento Rompizales en el entorno de la capital burgalesa, donde el rango de cerámica decorada con motivos campaniformes -aquí principalmente de vajilla fina- alcanza idéntico porcentaje para un número de estructuras arqueológicas domésticas también similar (ALONSO, 2003: 123). El grado de fragmentación del conjunto cerámico y su porcentaje decorado mantiene igualmente un buen paralelo en los niveles campaniformes de Champ-Vully Est en Rances (Vaud, Suiza), con un rango que se eleva al $20 \%$ de las piezas cuando se incluyen aspectos tipológicos (BESSE Y DESIDERI, 2005: 71). Por lo tanto, ¿cuál sería la explicación para justificar en contextos domésticos semejante esfuerzo invertido en la elaboración de tan cuantioso número de cerámicas de uso común, si se aleja toda sombra de una cuestión étnica? Desde luego moda, no, ya que si hay algo que define a los grupos campaniformes aquí y allá es la tradición.

La tradición explica la pervivencia de algunos motivos decorativos muy minoritarios en el repertorio campaniforme con una distancia temporal de no menos de 500 años -en fechas absolutas- entre Valdescusa y El Hundido (ALONSO, 2013a: 101), inmovilismo que igualmente se rastrea en los motivos decorativos del contexto riojano (BARRIOS, 2004: 143; ALDAY, 2005: 276). Un dislate temporal compadece en el package cerámico puramente calcolítico de acompañamiento al conjunto campaniforme de Rompizales, situado cronológicamente en el apogeo del Bronce Antiguo, mientras que en el epicampaniforme francés la tradición decorativa incorpora novedades formales en la diversificación de los nuevos conjuntos cerámicos (LEMERCIER, 1998: 377).

Este inmovilismo del registro material entra en contradicción con la adopción de prácticas rituales del momento como son los enterramientos secundarios de juveniles-adultos en fosa documentados en nuestro yacimiento, sin ale- jarse por ello del carácter individual y la pauta que define el modelo campaniforme más común, pero no estándar. En el aspecto ritual, la tradición explica la intrusión y reutilización de sepulcros colectivos anteriores, especialmente megalíticos, buscando probablemente su legitimación y el consiguiente reforzamiento de nuevas estructuras sociales, pauta que concurre con mayor intensidad en los momentos iniciales del fenómeno antes de la consolidación de las jefaturas de la Edad del Bronce. No obstante, en los dólmenes riojanos de Peña Guerra I y II se produce una manifestación también retardaría a la luz de las fechas radiocarbónicas disponibles (NAVARTE, 2005: 210, 217), sincrónica al registro funerario documentado en Valdescusa.

Por su parte, la personalidad de muchos poblados, que en el área analizada tienden a ocupar nichos de llanura-paramera, con poca expresividad en su economía agrícola y una base ganadera principalmente de ovicápridos en parcial oposición a los de grupos coetáneos no campaniformes del Bronce Antiguo-Medio abre, además, una cuestión de fondo sobre la que no debiera pasarse página definitivamente: ¿existe realmente una 'cultura campaniforme' con lo que étnicamente puede ello comportar, o bien se tratan de simples elementos de alto valor simbólico integrados en la comunidades locales? Parafraseando a Clark, desde nuestro punto de vista la segunda premisa no explica la existencia de 'poblados campaniformes', como Valdescusa o Rompizales, aunque sí de poblados 'con campaniforme', incorporando en el mismo cajón de sastre lugares de hábitat que, a la luz del registro arqueológico, se muestran heterogéneos. Ello no es excluyente del alto valor simbólico que poseen una parte de los repertorios cerámicos campaniformes en los contextos funerarios más antiguos, como así se ha demostrado con el consumo de cerveza y silicernia asociados al aspecto ritual (ROJO et al., 2005: 244). También explicaría intercambios culturales entre los distintos grupos donde 'lo campaniforme' hace acto de tibia presencia.

Como en todo proceso estadístico se precisa de un universo mínimo de muestreo, por lo que la nómina de yacimientos estudiados de forma sistemática debe incrementarse notablemente para alcanzar bases de trabajo válidas, encontradas o no, ya sean particulares o generales. Solo un enfoque bioarqueológico mediante análisis antropológicos, isotópicos y de ADN deberá invalidar definitivamente, o no, la idea étnica de un 'pueblo campaniforme' y sus distintos ritmos en el contexto regional, peninsular y europeo. En este sentido, algunos hallazgos como el célebre 'arquero de Amesbury' en Wiltshire (FITZPATRICK, 2003: 630) demuestran, a partir del análisis isotópico, una amplia movilidad de personas. En los conjuntos centro-europeos estudiados esta movilidad alcanza entre el $50 \%$ y $60 \%$, sin distinción de sexos ni rangos de edad (PRICE et al., 2004: 31), movimiento de grupos que parece incontestable en el estado actual de la cuestión para explicar la difusión del fenómeno (SALANOVA, 2005: 10). Estos movimientos se asumen como naturales en la Francia mediterránea, donde se habla de dos sustratos diferenciados -indígena y campaniforme- con niveles de interacción distintos y cuya difusión es marcadamente diferencial, por 
ejemplo, entre el oriente y occidente de la región de Languedoc (GUILAINE et al., 2001; AMBERT, 2003).

Sin duda alguna, acotar, periodizar y definir las particularidades regionales contribuirá decisivamente a conciliar la parte que tiene de cultura y de fenómeno cultural esta manifestación arqueológica tan amplia y diversa, no debiendo excluirse nuevas posibilidades en su exploración en sintonía con los postulados para el estudio peninsular de la Prehistoria Reciente (GILMAN, 2003). Lo cierto es que actualmente podemos bosquejar regiones con personalidad campaniforme muy definida, en una de las cuales Valdescusa se inserta, y que mantienen concomitancias con otras del contexto peninsular y europeo, dando valor a argumentos denostados sobre la extensión del fenómeno en el Bronce Medio y las implicaciones que ello puede tener para acercarnos a su comprensión.

\section{6.- AGRADECIMIENTOS}

Queremos manifestar nuestro agradecimiento a Pilar Duarte Garasa, Responsable del Programa Arqueológico en La Rioja, por el interés y las facilidades mostradas durante el desarrollo de los trabajos, así como por la financiación de determinadas pruebas diagnósticas por parte del Gobierno de La Rioja. También a Pedro Beneítez, del Laboratorio de Datación y Radioquímica de la Universidad Autónoma de Madrid, responsable de la datación por termoluminiscencia de las muestras cerámicas; y a Kurt W. Alt, del Institute of Antropology de la Universidad de Mainz, director del programa 'Reconstruction of population dynamic processes in the Iberian Peninsula between the Neolithic and Early Bronze Age through ancient DNA analyzes' donde se han integrado las muestras del yacimiento.

\section{BIBLIOGRAFÍA}

\section{ABARQUERO MORAS, F.J.}

2005 Cogotas I. La difusión de un tipo cerámico durante la Edad del Bronce. Junta de Castilla y León. Valladolid.

\section{ALDAY RUIZ, A}

1996 Reflexiones en torno al Campaniforme: una mirada hacia el caso vasco. Zephyrus XLVIII, 143-186.

2005 Estado de la cuestión Campaniforme en la Alta y Media cuenca del Ebro, en ROJO GUERRA, M.A., GARRIDO PENA, R. Y GARCÍA MARTÍNEZ DE LAGRÁN, I. (Coords). El Campaniforme en la Península Ibérica y su contexto europeo. 263-281. Junta de Castilla y León, Universidad de Valladolid. Salamanca.

\section{ALIAGA ALMEDA, R.}

2008 El mundo funerario calcolítico de la región de Madrid. Cuadernos de Arqueología y Prehistoria 34, 23-39.

\section{ALONSO FERNÁNDEZ, C}

2003 Excavación arqueológica en el yacimiento Rompizales (Monte de la Abadesa, Burgos). Informe inédito. 2013a Las tumbas campaniformes del monumento funerario 'El Hundido' (Monasterio de Rodilla, Burgos). Munibe Antropologia-Arkeologia 64, 89-103.

2013b Excavación y documentación arqueológica del yacimiento 'Valdescusa' de Hervías (La Rioja). Informe inédito.

ALONSO FERNÁNDEZ, C. Y JIMÉNEZ ECHEVARRÍA, J.

2012a El tránsito Protocogotas/Cogotas I Pleno en el límite de la zona nuclear: análisis comparativo de tres yacimientos de la comarca del Arlanzón (Burgos), en RODRÍGUEZ MARCOS, J.A. Y FERNÁNDEZ MANZANO, J. (Eds). Cogotas I. Una cultura de la Edad del Bronce en la Península lbérica. 361-376. Universidad de Valladolid. Valladolid.

2012b El depósito de armas de 'Los Cascajos' (Grañón, La Rioja): un conjunto broncíneo de importación en el límite del área nuclear Cogotas I, en RODRÍGUEZ MARCOS, J.A. Y FERNÁNDEZ MANZANO, J. (Eds). Cogotas I. Una cultura de la Edad del Bronce en la Península Ibérica. 397-407. Universidad de Valladolid. Valladolid.

2014 Contribución al estudio del poblamiento, modos de vida y ritual funerario del Neolítico Antiguo: el asentamiento al aire libre de El Prado (Pancorbo, Burgos). Zephyrus LXXIV, 9-14.

AMBERT, P.

2003 Contribution à l'étude du Campaniforme du Languedoc central meridional. Bulletin de la Sociétè préhistorique française 100(4), 715-732.

BARRIOS GIL, I.

2004 El yacimiento de Cueva Lóbrega (Torrecilla en Cameros La Rioja). Una visión acerca del Neolítico y la Edad del Bronce en el área occidental del Sistema Ibérico. HistoriaArqueología 15, IER. Logroño.

BENZ, M., STRAHM, C. Y VAN WILLIGEN, S.

1998 Le Campaniforme: phénomène et culture archaéologique. Bulletin de la Sociétè préhistorique française 95(3), 305-314.

BERZOSA DEL CAMPO, R. Y FLORES DÍAZ, M.

2005 El conjunto funerario Campaniforme del Vertedero de 'La Salmedia' (Distrito Villa de Vallecas, Madrid) en ROJO GUERRA, M.A., GARRIDO PENA, R. Y GARCIÍA MARTÍNEZ DE LAGRÁN, I. (Coords). El Campaniforme en la Península Ibérica y su contexto europeo. 481-490. Junta de Castilla y León - Universidad de Valladolid. Salamanca.

BESSE, M. Y DESIDERI, J.

2005 La diversidad Campaniforme: Hábitats, sepulturas y cerámicas, en ROJO GUERRA, M.A. GARRIDO PENA, R. Y GARCÍA MARTÍNEZ DE LAGRÁN, I. (Coords). El Campaniforme en la Península Ibérica y su contexto europeo. 61-88. Junta de Castilla y León - Universidad de Valladolid. Salamanca.

CAMPILLO CUEVA, J.

2000-02 La importancia del desfiladero de Pancorbo (Burgos) durante la época Campaniforme. Kobie XXVI, 85-108.

\section{CENICEROS HERREROS, J.}

2000 Sondeo arqueológico realizado en el yacimiento del bronce medio de Majada Londeras. Estrato 12, 4-7.

CLOP GARCÍA, X.

2004 Practiques funéraries du nord-est de la Péninsule Ibérique entre 3100-1500 avant J.C., en BESSE, M. Y DESIDERI J. (Eds.). Graves and funerary rituals during the 
Late Neolithic and the Early Bronce Age in Europe (2700-2000 BC). 29-40. British Archaeological Reports International Series 1525, Archaeopress. Oxford.

\section{FERNÁNDEZ-POSSÉ Y DE ARNÁIZ, M.D.}

1981 La cueva de Arevalillo de Cega (Segovia). Noticiario Arqueológico Hispánico 12, 43-84.

\section{FITZPATRICK, A.D.}

2003 The Amesbury Archer: a well-fumished Early Bronce Age burial in shothem England. Antiquity 76, 629-630.

\section{GARRIDO PENA, R.}

2000 El Campaniforme en La Meseta de la Península Ibérica (c.2500-2000 A.C.). British Archaeological Reports International Series 892, Archaeopress. Oxford.

GARRIDO PENA, R., ROJO GUERRA, M. Y GARCÍA MARTÍNEZ DE LAGRÁN, I.

2005 El Campaniforme en la Meseta central de la Península Ibérica, en ROJO GUERRA, M.A., GARRIDO PENA, R. Y GARCIIA MARTÍNEZ DE LAGRÁN, I. (Coords.). EI Campaniforme en la Peninsula Ibérica y su contexto europeo. 411-435. Junta de Castilla y León, Universidad de Valladolid. Salamanca.

\section{GILMAN, A.}

2003 El impacto del radiocarbono sobre el estudio de la Prehistoria tardía de la Península Ibérica: breves comentarios. Trabajos de Prehistoria 60(2), 7-13.

\section{GUILAINE J., CLAUSTRE F., LEMERCIER O. Y SABATIER P.}

2001 Campaniforme et environnement culturel en France méditerranéenne, en NICOLIS F. (Ed.). Bell Beakers today. Pottery, people, culture, symbols in prehistoric Europe. Proceedings of the International Colloquium, Riva del Garda (Trento, Italy), 11-16 May 199 8(Vol. I). 229-275.

HARRISON, R.J.

1980 The Beaker Folk. Copper Age archaeology in Western Europe. Thames and Hudson. London.

\section{LEMERCIER, O}

1998 Phénomène culture et tradition: status et rôles du Campaniforme au Ille millénaire dans le Sud-Est de la France. Bulletin de la Société préhistorique française 95(3), 365-382.

LIESAU, C., BLASCO, C. RÍOS, P., VEGA, J., MENDUIÑA, R., BLANCO, J.F., BAENA, J., HERRERA, T., PETRI, A. Y GÓMEZ, J.L.

2008 Un espacio compartido por vivos y muertos: El poblado calcolítico de fosos de Camino de las Yeseras (San Fernando de Henares, Madrid). Complutum 19, 97-120.

\section{LIESAU, C., ESPARZA, A. Y SÁNCHEZ, A.}

2014 ¿Huesos en la basura o depósito ritualizado? Los perros descuartizados de La Huelga (Dueñas, Palencia). Zephyrus LXXIV, 89-115.

LÓPEZ PADILLA, J.A., MIGUEL IBÁÑEZ, M.P., ARNAY DE LA ROSA, M., GALINDO' MARTÍN, L., ROLDÁN' GARCÍA, C. Y MURCIA MASCARÓS, S.

2012 Ocre y cinabrio en el registro funerario de El Argar. Trabajos de Prehistoria 69(2), 273-292.
MAICAS RAMOS, R.

2007 Industria ósea y funcionalidad: Neolítico y Calcolítico en la cuenca de Vera (Almería). Bibliotheca Praehistorica Hispana, CSIC. Madrid.

METCALF, P. Y HUNTINTON, R.

1991 Celebrations of Death: The Anthropology of mortuary ritual. Cambridge University Press. Cambridge.

NARVARTE SANZ, N.

2005 Gestión funeraria dolménica en la cuenca alta y media del Ebro: fases de ocupación y clausura. Historia-Arqueología 16, IER. Logroño.

PÉREZ ARRONDO, C.L., CENICEROS HERREROS, J. Y DUARTE GARASA, $P$.

1987 Aportaciones al estudio de las culturas eneolíticas en el Valle del Ebro. III: La cerámica. Historia 9, IER. Logroño.

PRICE, T.D., KNIPPER, C., GRUPE, G. Y SMRCKA, V.

2004 Stromtium isotopes and prehistoric human migration: the Bell Beaker period in central Europe. European journal of archaeology 7(1), 9-40.

RODANÉS VICENTE, J.M

1999 Las cuevas de Tragaluz y San Bartolomé (Sierra de Cameros, la Rioja). Los enterramientos en cueva en el Valle Medio del Ebro. Historia 13, IER. Logroño.

ROJO GUERRA, M.A., KUNST, M., GARRIDO PENA, R., GARCIIA MARTIINEZ DE LEGRÁN, I. Y MORÁN DAUCHEZ, G.

2005 Un desafío a la eternidad: tumbas monumentales del Valle de Ambrona. Junta de Castilla y León. Valladolid.

SALANOVA, L.

2005 Los orígenes del campaniforme: descomponer, analizar, cartografiar, en ROJO GUERRA, M.A., GARRIDO PENA, R. Y GARCÍA MARTÍNEZ DE LAGRÁN, I. (Coords.). El Campaniforme en la Península Ibérica y su contexto europeo. 7-27. Junta de Castilla y León - Universidad de Valladolid. Salamanca.

SÁNCHEZ MESENGUER, J.L. Y GALÁN SAULNIER, C.

2010 C14 y cerámica campaniforme en la cueva de Pedro Fernández Villacañas (Estremera, Madrid). Espacio, Tiempo y Forma. Serie I, Nueva Época, Prehistoria y Arqueología 3, 73-106.

SESMA SESMA, J.

1993 Aproximación al problema del hábitat campaniforme: el caso de las Bardenas Reales de Navarra. Cuadernos de Arqueología de la Universidad de Navarra 1, 53-120.

SESMA SESMA, J. Y GARCÍA GARCÍA, M.L.

2002-03 Los yacimientos de Covaza y Picarana (Pitillas, Navarra): algunos datos sobre la Edad del Bronce en la Navarra Media. Trabajos de Arqueología de la Navarra 16, 15-44. 